\title{
Indiplon in the management of insomnia
}

This article was published in the following Dove Press journal:

Drug Design, Development and Therapy

7 May 2009

Number of times this article has been viewed

\author{
Michael D Lemon' \\ Joe D Strain ${ }^{2}$ \\ Annie M Hegg' \\ Debra K Farver ${ }^{3}$ \\ 'Department of Pharmacy Practice, \\ South Dakota State University \\ College of Pharmacy, VA Black Hills \\ Health Care System, Fort Meade, \\ SD, USA; ${ }^{2}$ Department of Pharmacy \\ Practice, South Dakota State \\ University College of Pharmacy, \\ Rapid City Regional Hospital, Rapid \\ City, SD, USA; ${ }^{3}$ Department of \\ Pharmacy Practice, South Dakota \\ State University College of Pharmacy, \\ South Dakota Human Services Center \\ Yankton, SD, USA
}

\begin{abstract}
Indiplon is a novel pyrazolopyrimidine, nonbenzodiazepine $\gamma$-aminobutyric acid (GABA) agonist studied for the treatment of insomnia. This article reviews the chemistry, pharmacology, clinical pharmacokinetics, drug interactions, clinical trials, safety, tolerability, contraindications, use in special populations, and dosing of indiplon. OVID, International Pharmaceutical Abstracts (IPA), and PubMed databases were searched (1966 to February 2009) for the keywords indiplon, NBI-34060, and insomnia. References of key articles were also reviewed to identify additional publications. Only English language articles were selected for review. Indiplon has been shown to have high affinity and selectivity for the GABA $\alpha_{1}$ receptor subunit associated with sedation. In clinical studies, indiplon has demonstrated efficacy in improving latency to sleep onset, latency to persistent sleep, total sleep time, wake time after sleep onset, number of awakenings after sleep onset, and overall sleep quality when compared to placebo. Indiplon has a favorable safety profile with limited rebound insomnia and no tolerance. Neurocrine Biosciences, Incorporated received an Approvable Letter from the United States Food and Drug Administration in December 2007 for the indiplon IR $5 \mathrm{mg}$ and $10 \mathrm{mg}$ capsules based on meeting three additional requirements. At the time of this writing, indiplon remains unapproved.
\end{abstract}

Keywords: indiplon, insomnia, NBI-34060

\section{Introduction}

The diagnostic criteria for primary insomnia, from the Diagnostic and Statistical Manual of Mental Disorders fourth edition, text revision (DSM-IV-TR), includes difficulty falling asleep, intermittent wakefulness during sleep and/or nonrestorative sleep (poor quality sleep) for at least one month. ${ }^{1}$ From the 2005 Sleep in America Poll, the symptoms reported at least a few nights a week with insomnia were waking up feeling unrefreshed (38\%), awake a lot at night (32\%), difficulty falling asleep (21\%), and woke up too early and could not get back to sleep (21\%). ${ }^{2}$ Clinically, patients can be impacted in their social and occupational functioning. Daytime consequences such as fatigue, decreased attention, decreased energy, along with lack of motivation, and deteriorated mood may occur. Approximately one-third of adult Americans experience symptoms of insomnia intermittently, while 10\%-15\% report having chronic insomnia.,

Treatment options for insomnia include cognitive behavioral therapy and/or pharmacologic therapy. ${ }^{5-7}$ The pharmacologic classes prescribed for insomnia include benzodiazepines, nonbenzodiazepine sedative hypnotics, melatonin receptor agonists, antidepressants with sedating properties, and sedating antihistamines. Indiplon is a
Correspondence: Michael D Lemon VA Black Hills Health Care System, I I 3 Comanche Rd, Pharmacy Service, Fort Meade, South Dakota 5774I-1099, USA $\mathrm{Tel}+\mathrm{I} 6057207107$

Fax +l 6053477207

Email michael.lemon@va.gov 
nonbenzodiazepine sedative hypnotic with more selectivity for $\gamma$-aminobutyric acid (GABA) receptors with the $\alpha_{1}$ subunit. ${ }^{8,9}$

Neurocrine Biosciences, Incorporated (Inc) (San Diego, CA, USA) has researched immediate (IR) and modified release (MR) formulations of indiplon. On May 15, 2006, the US Food and Drug Administration (FDA) granted an Approvable Letter for indiplon IR $5 \mathrm{mg}$ and $10 \mathrm{mg}$ capsules. ${ }^{10}$ The FDA also requested a reanalysis of certain study data to support the indications of sleep initiation and middle of the night dosing, a reanalysis of safety data for the elderly, and a supplemental pharmacokinetic/food effect trial. A New Drug Application for indiplon IR was resubmitted to the FDA on June 12, 2007. Indiplon IR received an Approvable Letter from the FDA in December 2007 for the $5 \mathrm{mg}$ and $10 \mathrm{mg}$ dosage forms based on meeting three additional requirements. The FDA requested a study in elderly patients, a study comparing adverse events of indiplon versus an approved product for the treatment of insomnia, and a preclinical study to evaluate its use in the third trimester of pregnancy. According to the Neurocrine Biosciences, Inc 2008 fourth quarter report, a meeting with the FDA occurred in July 2008 and the company is awaiting a final version of those minutes to determine the next step with indiplon. ${ }^{11}$ Currently indiplon is not reported as being approved for use in any other countries. ${ }^{10}$

Indiplon MR $15 \mathrm{mg}$ tablets received a Not Approvable Letter in May 2006. ${ }^{10}$ The not approvable status involved indiplon MR doses $>15 \mathrm{mg} / \mathrm{d}$ and insufficient sleep maintenance data. The FDA requested a long-term safety and efficacy trial for adults and the development of a separate MR dose for the elderly. At this time, the MR $15 \mathrm{mg}$ dose has not been resubmitted to the FDA.

This review will focus on the chemistry, pharmacology, clinical pharmacokinetics, drug interactions, clinical trials, adverse reactions, contraindications, use in special populations, and dosing of indiplon in the treatment of primary insomnia.

\section{Chemistry and pharmacology}

The $\mathrm{GABA}_{\mathrm{A}}$ receptor is a pentameric molecule composed of a combination of one or more specific subunit types. Although 19 different subunits are known to exist, ${ }^{12}$ the majority of $\mathrm{GABA}_{\mathrm{A}}$ receptors in the central nervous system consist of $\alpha_{(1-6)}, \beta_{(1-3)}$, and $\gamma_{(1-3)}$ subunits. ${ }^{13}$ The interaction of benzodiazepines with multiple $\mathrm{GABA}_{\mathrm{A}}$ receptor subunits containing $\alpha_{(1-3,5)}$ is thought to elicit the variety of effects seen with these agents such as anxiolysis, amnesia, muscle relaxation, sedation, and anticonvulsant activity. ${ }^{13,14}$ The $\alpha_{1}$-receptor subunit has been associated with inducing sedation. ${ }^{13,14}$ The theoretical advantage of having a selective $\alpha_{1}$ subunit agonist is that sedating effects are achieved while avoiding other effects thought to be mediated by the other $\alpha$ subunits to which benzodiazepines bind.

In contrast to benzodiazepines, the nonbenzodiazepine sedative hypnotics (ie, zolpidem, eszopiclone, zopiclone, zaleplon) are more selective for the $\mathrm{GABA}_{\mathrm{A}}$ receptors with the $\alpha_{1}$-receptor subunit. ${ }^{8}$ Indiplon, a new pyrazolopyrimidine sedative hypnotic, has been shown to have high affinity and selectivity for the $\alpha_{1}$ subunit associated with sedation. ${ }^{8,9}$ Petroski and colleagues ${ }^{15}$ showed indiplon to be at least nine times more selective for $\alpha_{1}$ as compared to $\alpha_{2}, \alpha_{3}$, and $\alpha_{5}$ subunits. ${ }^{15}$ This study further showed that the degree of selectivity for $\alpha_{1}$, over the $\alpha_{2}$ and $\alpha_{3}$ subunits, was greater for indiplon as compared to zolpidem, zopiclone, and zaleplon. The $\alpha_{2}$ subunit is involved in producing anxiolytic effects. ${ }^{13}$ The 9.3 times lower affinity of indiplon to the $\alpha_{2}$ vs $\alpha_{1}$ subunit suggests it does not have significant anxiolytic properties. $^{15}$

Continual use of benzodiazepines such as triazolam has been associated with the development of tolerance during intermediate and long-term use. ${ }^{16}$ Although tolerance has been reported less with agents such as zolpidem, ${ }^{16}$ it remains important to evaluate these parameters for agents used for inducing sleep. Jochelson and colleagues ${ }^{17}$ studied 30 healthy males, aged 22-41, to identify pharmacokinetic or pharmacodynamic tolerance associated with indiplon. Study subjects were prescribed indiplon $10 \mathrm{mg}, 30 \mathrm{mg}$, or $45 \mathrm{mg}$ once daily for 14 consecutive days. The pharmacokinetic and pharmacodynamic analysis showed similar results on day 1 as compared to day 14 concluding no tolerance was associated with indiplon. Moscovitch and colleagues ${ }^{18}$ also reported no evidence of tolerance in a six-month elderly study. The mean number of indiplon IR doses throughout the study was 22 per month. Indiplon's high selectivity for the $\alpha_{1}$-subunit, as well as a short half-life may theoretically contribute to its lack of tolerance. ${ }^{15}$

\section{Clinical pharmacokinetics}

Indiplon is extensively metabolized in the liver to two major inactive metabolites. ${ }^{19}$ The CYP3A4/5 enzyme primarily accounts for the formation of N-desmethylindiplon $(60 \%-70 \%)$ while carboxylesterase enzymes form $\mathrm{N}$-desacetyl indiplon $(30 \%-40 \%)$. A secondary inactive metabolite, $\mathrm{N}$-desmethyl-N-desacetyl-indiplon, is produced 
by the $\mathrm{N}$-demethylation of $\mathrm{N}$-desacetyl-indiplon as well as the $\mathrm{N}$-deacetylation of $\mathrm{N}$-desmethyl-indiplon. Less than $1 \%$ of indiplon is eliminated in the urine or feces as unchanged drug.

Animal data show indiplon attains a peak plasma level (Tmax) in 30 minutes and has a half-life of 60 minutes. ${ }^{8}$ A human trial by Rogowski and colleagues ${ }^{20}$ administered indiplon IR $15 \mathrm{mg}$ orally to all subjects and revealed the Tmax in males was 0.73 hours with a half-life of 1.97 hours. In female subjects, the Tmax was 0.82 hours with a half-life of 1.71 hours. Although this trial included only 24 subjects, no statistically significant gender differences were found in regards to indiplon's pharmacokinetics. Jochelson and colleagues ${ }^{21}$ evaluated 12 adults aged 18-45 and compared them to 13 elderly subjects aged 65-79. After one oral dose of indiplon IR $15 \mathrm{mg}$, the mean Tmax in the younger adult population was 2.3 hours compared to 2.7 hours in the elderly group. The mean half-life of indiplon was 1.5 hours in the young adults and 1.8 hours in the elderly group. Statistical evaluation of this data determined no significant differences exist between the young and elderly populations. This study included similar numbers of males and females in each group and also determined no differences in gender exist in regards to indiplon pharmacokinetics. The carboxylesterase metabolic pathway, which is less affected by age and not known to have gender differences, is one of the proposed reasons for similar pharmacokinetics seen across these populations. ${ }^{20,21} \mathrm{~A}$ trial by Bozigian and colleagues ${ }^{22}$ further evaluated the pharmacokinetics of indiplon $10 \mathrm{mg}$, $15 \mathrm{mg}, 20 \mathrm{mg}$, and $30 \mathrm{mg}$ daily in 24 young healthy males. A dose-dependent linear increase in area under the curve (AUC) as well as a proportional dose-dependent increase in maximum concentration was evident. The Tmax was about one hour for all doses and the half-life varied from 2.59-3.82 hours.

\section{Drug interactions}

Ketoconazole, troleandomycin, and erythromycin are inhibitors of the CYP3A4 enzyme and have been shown to decrease the metabolism of indiplon. ${ }^{19}$ Ketoconazole increased the plasma AUC by 2.4-fold while erythromycin increased indiplon's plasma AUC by 1.25 -fold. The alternative route of carboxylesterase metabolism may explain why the change in plasma AUC due to a highly potent inhibitor like ketoconazole is limited to a 2.4-fold increase. Indiplon was also studied in conjunction with sertraline and paroxetine and no changes in indiplon pharmacokinetics were seen, nor were there any pharmacodynamic changes in regards to tests of psychomotor function and alertness. ${ }^{23}$ Concomitant use of rifampin, a CYP3A4 inducer, has been shown to reduce the plasma AUC of indiplon by $70 \%{ }^{19}$

Indiplon is a weak inhibitor of CYP450 enzymes, and is not expected to cause any clinically significant inhibition of other medications. ${ }^{19}$ Abel and colleagues ${ }^{24}$ studied indiplon use in conjunction with aminophylline, digoxin, and warfarin and revealed indiplon did not affect the pharmacokinetics of any of the drugs studied. Indiplon does not induce the CYP1A2 or CYP3A4 enzymes and thus is not expected to cause any significant interaction through enzyme induction. ${ }^{19}$ Interactions with the carboxylesterase metabolism pathway are not expected, as no currently marketed drugs are known to inhibit these enzymes.

Berkowitz and colleagues ${ }^{25}$ studied the interaction of ethanol with indiplon. Ten male subjects were randomized to indiplon $10 \mathrm{mg}$, ethanol $0.7 \mathrm{mg} / \mathrm{ml}$, or both. Indiplon's peak plasma level at one hour and half-life were not affected by ethanol. The Digital Symbol Substitution Test (DSST) and Symbol Copying Test (SCT) were utilized to evaluate performance. DSST involves measuring cognitive function by giving a subject 90 seconds to use a nine digit code key and substitute the correct symbol for each digit shown on the test. ${ }^{26}$ A lower score on the DSST indicates more impairment. The SCT assesses the motor component of the DSST by asking the subject to copy the same numbers used in the DSST. Based on the DSST and SCT, a slight decrease in performance was evident when indiplon and ethanol were combined, however no effect on sedation or reaction time was seen. ${ }^{25}$ Different metabolic pathways easily explain the lack of pharmacokinetic interaction, however the minimal pharmacodynamic interaction is not as well defined. The lack of interaction of indiplon with the $\alpha_{2}$ subunit has been proposed as a possible reason for the lack of a pharmacodynamic interaction with ethanol. ${ }^{15}$

\section{Clinical studies}

Indiplon IR efficacy and safety was evaluated in 10 randomized, double-blind, placebo controlled trials, ${ }^{26-33}$ and one open label extension trial. ${ }^{18}$ The efficacy of indiplon MR was evaluated in four randomized, double-blind, placebo controlled trials. ${ }^{34-37}$ Trial data is summarized in Table $1^{26-31}$ for indiplon IR in adults, Table $2^{18,26,32,33}$ for indiplon IR in the elderly, and Table $3^{34-37}$ for indiplon MR. Table 4 provides a summary of the clinical efficacy terms used in the indiplon studies. ${ }^{38-40}$ It should be noted that Neurocrine Biosciences, Inc sponsored all the studies and many of the studies are only available in abstract form. 
Table I Clinical efficacy trials of indiplon IR in adults

\begin{tabular}{|c|c|c|c|c|c|}
\hline Author (year) & $\mathbf{N}$ & $\begin{array}{l}\text { Age range } \\
\text { in years (Mean) }\end{array}$ & Duration & Dose (mg) & Outcomes \\
\hline Farber $(2008)^{26}$ & 35 & $18-45(32.4)$ & $\begin{array}{l}\text { One night } \\
\text { per arm }\end{array}$ & $\begin{array}{l}\text { indiplon 10,20 placebo } \\
\text { zolpidem } 10 \text { zopiclone } 7.5\end{array}$ & $\begin{array}{l}\text { No change in DSST, SCT, VAS-S for indiplon at } \\
4 \text { and } 6 \text { hours post-dose. } \uparrow \text { VAS-S for zolpidem } \\
\text { at } 4 \text { hours. } \uparrow \text { VAS-S for zopiclone at } 4 \text { and } \\
6 \text { hours. No change in DSST and SCT for } \\
\text { zolpidem and zopiclone at } 4 \text { and } 6 \text { hours. }\end{array}$ \\
\hline Roth $(2007)^{27}$ & 264 & $18-64(46)$ & Four weeks & indiplon 10,20 placebo & $\begin{array}{l}\downarrow \text { LSO }, \downarrow \text { sWASO }(20 \mathrm{mg} \text { only), } \downarrow \text { sNAASO } \\
(20 \mathrm{mg} \text { only), } \uparrow \text { sTST, } \uparrow \text { sleep quality }\end{array}$ \\
\hline Walsh $^{a}(2004)^{28}$ & 194 & Range NR (40.2) & Five weeks & indiplon 10,20 placebo & $\begin{array}{l}\downarrow \text { LPS, } \downarrow \text { sLSO, } \uparrow \text { TST (I } 0 \text { mg, week I only), } \\
\uparrow \text { sleep quality (week I only) }\end{array}$ \\
\hline Rosenberg $(2007)^{29}$ & 593 & $21-64(32)$ & One night & indiplon 10,20 placebo & $\begin{array}{l}\downarrow \text { LPSc }^{c} \uparrow \text { TST, } \downarrow \text { NAASO (20 mg only), } \\
\downarrow \text { WASO (20 mg only), } \uparrow \text { sleep quality }\end{array}$ \\
\hline $\operatorname{Roth}^{\mathrm{a}}(2003)^{30}$ & 228 & $18-59$ (NR) & One night & indiplon $15^{b}, 30^{b}$ placebo & $\downarrow$ LPS, $\downarrow$ LSO, No change TST \\
\hline Scharf $(2007)^{31}$ & 702 & $21-64(46)$ & Three months & indiplon 10,20 placebo & $\begin{array}{l}\downarrow \text { sLSO } c, \uparrow \text { sTST, } \downarrow \text { sWASO, } \downarrow \text { sNAASO, } \\
\uparrow \text { sleep quality }\end{array}$ \\
\hline
\end{tabular}

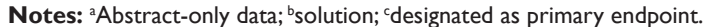

Abbreviations: DSST, digit symbol substitution test; LSO, latency to sleep onset; LPS, latency to persistent sleep; NAASO, number of awakenings after sleep onset; NR, not reported; s, subjective or self; SCT, symbol copying test;TST, total sleep time;VAS-S, visual analog scale of sleepiness;WASO, wake after sleep onset.

\section{Immediate release indiplon}

\section{Adult studies}

Efficacy of indiplon IR was evaluated in patients meeting DSM-IV criteria for primary insomnia with nocturnal awakenings. ${ }^{27}$ Patients received indiplon IR $10 \mathrm{mg}, 20 \mathrm{mg}$, or placebo. This was a post-bedtime dose study and most patients took the medication between the hours of 12:00 AM and 2:00 AM. The mean number of doses taken per week was $3.9 \pm 1.9,3.7 \pm 1.7$, and $3.7 \pm 1.9$ for the $10 \mathrm{mg}, 20 \mathrm{mg}$, and placebo groups, respectively. All study outcomes were subjectively measured. The primary outcome was patient rated latency to sleep onset (LSO) post-dose in which the fourweek average was decreased to mean \pm standard error of mean (SEM) values of $36.5 \pm 1.8$ minutes $(p=0.0023)$ in the $10 \mathrm{mg}$ group, $34.4 \pm 1.7$ minutes ( $<<0.0001)$ in the $20 \mathrm{mg}$ group, and $45.2 \pm 2.2$ minutes in the placebo group. Average total sleep time (TST) improved significantly at $253 \pm 6.8$ minutes in the $10 \mathrm{mg}$ group $(\mathrm{p}=0.0099)$ and $278 \pm 6.5$ minutes in the $20 \mathrm{mg}$ group $(\mathrm{p}<0.0001)$, compared to $229 \pm 6.6$ minutes in the placebo group. Baseline values for the wake time after sleep onset (WASO) were $27.5 \pm 4.6$ minutes for the placebo group, $31.7 \pm 4.7$ minutes for the $10 \mathrm{mg}$ group, and $37.7 \pm 4.6$ minutes for the $20 \mathrm{mg}$ group. Only in the $20 \mathrm{mg}$ group was the four-week average WASO significant with values of $24.4 \pm 3.5,16.2 \pm 3.6$, and $12 \pm 3.5$ minutes $(\mathrm{p}=0.0122)$ in the placebo, $10 \mathrm{mg}$, and $20 \mathrm{mg}$ groups, respectively. The number of awakenings after sleep-onset (NAASO) was significantly reduced only in the $20 \mathrm{mg}$ group $(\mathrm{p}=0.0125)$. Overall sleep quality was improved in both indiplon treatment groups compared to placebo $(10 \mathrm{mg}, \mathrm{p}=0.0007$ and $20 \mathrm{mg}$, $\mathrm{p}<0.0001)$. Next day residual effects as rated on the Visual Analog Scale for sleepiness (VAS-S) were significantly better for both the $10 \mathrm{mg}$ and $20 \mathrm{mg}$ groups as indicated by a $10 \mathrm{~mm}$ or greater improvement in the VAS-S for next day alertness compared to placebo ( $p<0.05$ ). VAS-S is a scale where study subjects rate their level of alertness or sleepiness on a VAS which ranges from very alert to very sleepy.

Walsh and colleagues ${ }^{28}$ examined indiplon IR $10 \mathrm{mg}$ or $20 \mathrm{mg}$ versus placebo over five weeks in patients with primary insomnia of at least three months duration. Results from week 1 for polysomnography (PSG) measuring latency to persistent sleep (LPS) demonstrated significant improvement in the $10 \mathrm{mg}$ and $20 \mathrm{mg}$ groups versus placebo. The values for LPS at week 1 were 27.7 minutes for the $10 \mathrm{mg}$ group $(\mathrm{p}<0.01)$ and 27.1 minutes for the $20 \mathrm{mg}$ group $(\mathrm{p}<0.05)$, in contrast to 36.9 minutes for the placebo group. At week 5 of the study, LPS values remained significant at 29.2 minutes $(\mathrm{p}<0.01)$ for the $10 \mathrm{mg}$ group and 24.8 minutes $(\mathrm{p}<0.05)$ for the $20 \mathrm{mg}$ group, versus 40.1 minutes in the placebo group. TST (no values reported) was significantly better than placebo only during week 1 in the $10 \mathrm{mg}$ group $(\mathrm{p}<0.02)$. At week 1, the LSO was significantly reduced compared to placebo with values of $49.8(\mathrm{p}<0.0001), 44.4(\mathrm{p}<0.003)$, and 72.5 minutes in the indiplon $10 \mathrm{mg}, 20 \mathrm{mg}$, and placebo groups, respectively. The LSO remained significantly better than placebo in both active treatments at week $5(\mathrm{p}<0.02$; no values reported). Sleep quality was only significantly better during week 1 in the $10 \mathrm{mg}$ and $20 \mathrm{mg}$ groups versus 
Table 2 Clinical efficacy trials of indiplon IR in the elderly

\begin{tabular}{|c|c|c|c|c|c|}
\hline Author (year) & $\mathbf{N}$ & $\begin{array}{l}\text { Age range } \\
\text { in years (Mean) }\end{array}$ & Duration & Dose (mg) & Outcomes \\
\hline Walsh $(2007)^{32}$ & 358 & 65-80 (7I) & Two weeks & indiplon 5, 10 placebo & $\begin{array}{l}\downarrow \text { sLSO, } \uparrow \text { sTST, } \downarrow \text { sWASO } \\
\text { (except } 5 \text { mg at week I), } \\
\downarrow \text { sNAASO, } \uparrow \text { sleep quality }\end{array}$ \\
\hline Moscovitch $^{\mathrm{a}}(2006)^{18}$ & $|2|$ & $65-80(7 I)$ & Six months & indiplon 5,10 & $\begin{array}{l}\text { Self-reported insomnia } \\
\text { improvement: } 72 \% \text { (5 mg) 92\% } \\
(10 \mathrm{mg})\end{array}$ \\
\hline Scharfa $(2003)^{33}$ & 42 & $65-82(70)$ & Two nights per arm & indiplon $5,10,20$ placebo & $\begin{array}{l}\downarrow \text { LPS, } \downarrow \text { sLSO, } \uparrow \text { TST } \\
(10,20 \mathrm{mg} \text { only })\end{array}$ \\
\hline Farber $(2008)^{26}$ & 36 & $65-80(68.6)$ & One night per arm & $\begin{array}{l}\text { indiplon } 5,10 \text { placebo } \\
\text { zopiclone } 3.75\end{array}$ & $\begin{array}{l}\text { No change in VAS-S or SCT } \\
\text { for all indiplon treatments. No } \\
\text { change in DSST for indiplon } 5 \mathrm{mg} \text {. } \\
\downarrow \text { DSST for indiplon } 10 \mathrm{mg} \text { at } 4 \text { h, } \\
\text { but not at } 6 \text { and } 8 \text { hours. } \downarrow \text { DSST } \\
\text { for zopiclone at } 4 \text { and } 8 \text { hours, } \\
\text { but not at } 6 \text { hours. }\end{array}$ \\
\hline
\end{tabular}

Note: ${ }^{a}$ Abstract-only data.

Abbreviations: DSST, digit symbol substitution test; LSO, latency to sleep onset; LPS, latency to persistent sleep; NAASO, number of awakenings after sleep onset; s, subjective or self; SCT, symbol copying test;TST, total sleep time; VAS-S, visual analog scale of sleepiness; WASO, wake after sleep onset.

placebo ( $\mathrm{p}<0.03$; no values reported). No difference in next day residual effects was noted between the placebo and indiplon groups.

The efficacy of indiplon was also examined in two studies using a transient model of insomnia. ${ }^{29,30}$ The first study evaluated the efficacy of indiplon IR $10 \mathrm{mg}$ and $20 \mathrm{mg}$ doses in healthy volunteers using an experimental model of transient insomnia induced by sleeping in an unfamiliar place and a twohour earlier bedtime..$^{29}$ LPS values as measured by PSG were significantly decreased in the $10 \mathrm{mg}$ group to $21.2 \pm 1.5$ minutes and in the $20 \mathrm{mg}$ group to $16.8 \pm 1.1$ minutes, compared to the placebo group at $33.1 \pm 2.5$ minutes $(\mathrm{p}<0.0001)$. TST as measured by PSG was significantly increased in both the $10 \mathrm{mg}$ and $20 \mathrm{mg}$ groups compared to placebo with mean values of $414.5 \pm 3.9$ minutes $(p=0.0044), 423.5 \pm 3.1$ minutes ( $\mathrm{p}<0.0001)$, and 402.9 \pm 3.9 minutes, respectively. NAASO as measured by PSG was significantly decreased only in the $20 \mathrm{mg}$ group and the median values were 7 in the $10 \mathrm{mg}$ group $(\mathrm{p}=0.0583), 6$ in the $20 \mathrm{mg}$ group $(\mathrm{p}=0.0084)$, and 8 in the placebo group. WASO as measured by PSG was significantly decreased only in the $20 \mathrm{mg}$ group with mean values of $49.9 \pm 2.9$ in the placebo group, $48.7 \pm 3.5(\mathrm{p}=0.2540)$ in the $10 \mathrm{mg}$ group, and $42.5 \pm 2.8$ minutes $(\mathrm{p}=0.0091)$ in the $20 \mathrm{mg}$ group. Subjective sleep quality was significantly improved in both the $10 \mathrm{mg}(\mathrm{p}=0.0182)$ and $20 \mathrm{mg}$ groups compared to placebo ( $\mathrm{p}<0.0001$ ). No differences in next day residual effects were noted in either treatment group versus placebo. The second study which used the experimental transient insomnia regimen included healthy volunteers using indiplon $15 \mathrm{mg}$ or $30 \mathrm{mg}$ solution, versus placebo. ${ }^{30}$ PSG measured LPS was significantly decreased with mean values of 17.5 minutes in the $15 \mathrm{mg}$ group and 16.2 minutes in the $30 \mathrm{mg}$ group, compared to 34.1 minutes for placebo ( $\mathrm{p}<0.001)$. Significant improvement in subjective LSO was also noted with mean values of $15.8,15.4$, and 31.1 minutes for the $15 \mathrm{mg}, 30 \mathrm{mg}$, and placebo groups, respectively $(\mathrm{p}<0.001)$. No improvement in the PSG, TST, or subjectively measured TST was found in the indiplon groups versus placebo. Evaluation of next day effects found no difference between the indiplon and placebo groups.

Only one study has examined the long-term efficacy of indiplon. Scharf and colleagues ${ }^{31}$ evaluated indiplon IR $10 \mathrm{mg}$, $20 \mathrm{mg}$, or placebo in patients who met DSM-IV criteria for primary insomnia of at least three months duration. In the three-month study, all of the primary and secondary outcomes were subjectively measured through patient sleep diaries. At one month, mean LSO was significantly improved to $34 \pm 1.3$ minutes for $10 \mathrm{mg}(\mathrm{p}<0.0001)$ and $33.0 \pm 1.3$ minutes for $20 \mathrm{mg}$ ( $\mathrm{p}<0.0001$ ), compared to $48.7 \pm 1.9$ minutes for placebo. Significant efficacy was maintained for all three months for LSO in the active treatment groups compared to placebo. Mean TST was $327.5 \pm 4$ minutes at one month in the placebo group compared to $362.8 \pm 3.9$ minutes ( $\mathrm{p}<0.0001$ ) in the $10 \mathrm{mg}$ group, and $372.1 \pm 4$ minutes ( $\mathrm{p}<0.0001)$ in the $20 \mathrm{mg}$ group, and efficacy was statistically maintained for three months. WASO was $61.1 \pm 2.5$, $49.7 \pm 2.4(\mathrm{p}=0.0009)$, and $42.2 \pm 2.5$ minutes $(\mathrm{p}<0.0001)$ in the placebo, $10 \mathrm{mg}$, and $20 \mathrm{mg}$ groups, respectively at one month and this efficacy was maintained for the three-month 
Table 3 Clinical efficacy trials of indiplon MR in adults and elderly

\begin{tabular}{|c|c|c|c|c|c|}
\hline Author (year) & $\mathbf{N}$ & $\begin{array}{l}\text { Age range } \\
\text { in years (Mean) }\end{array}$ & Duration & Dose (mg) & Outcomes \\
\hline Jochelson $^{\mathrm{a}}(2004)^{35}$ & 211 & NR (48) & Two weeks & indiplon 30 , placebo & $\begin{array}{l}\uparrow \text { sTST }^{\text {b }}, \downarrow \text { LSO }, \downarrow \text { sWASO, } \downarrow \\
\text { sNAASO, } \uparrow \text { sleep quality }\end{array}$ \\
\hline Jochelson ${ }^{a}(2003)^{36}$ & 36 & $19-42$ (NR) & One night & indiplon 40 , placebo & $\begin{array}{l}\downarrow \text { sLSO, } \uparrow \text { sTST, } \uparrow \text { sleep } \\
\text { quality }\end{array}$ \\
\hline Lydiard $(2006)^{34}$ & 229 & 65-85 (7I) & Two weeks & indiplon I5, placebo & $\begin{array}{l}\downarrow \text { LSO }, \uparrow \text { sTST, } \downarrow \text { sWASO, } \downarrow \\
\text { sNAASO, } \uparrow \text { sleep quality }\end{array}$ \\
\hline Walsh $^{\mathrm{a}}(2003)^{37}$ & 60 & NR (69) & Two nights & $\begin{array}{l}\text { indiplon } 10,20,30,35 \text {, } \\
\text { placebo }\end{array}$ & $\begin{array}{l}\uparrow \mathrm{SE}(20,30,35 \mathrm{mg} \text { only), } \downarrow \\
\text { LPS, } \downarrow \text { WASO }(20,30,35 \mathrm{mg} \\
\text { only) }\end{array}$ \\
\hline
\end{tabular}

Notes: aAbstract-only data; ${ }^{b}$ primary endpoint.

Abbreviations: LSO, latency to sleep onset; LPS, latency to persistent sleep; NAASO, number of awakenings after sleep onset; NR, not reported; s, subjective; SE, sleep efficiency; TST, total sleep time;WASO, wake after sleep onset.

study duration. Significant improvement in mean NAASO was noted in the active treatment groups compared to placebo at one month with mean values of $1.6 \pm 0.1,1.3 \pm 0.1(\mathrm{p}<0.0001)$, and $1.1 \pm 0.1(\mathrm{p}<0.0001)$ in the placebo, $10 \mathrm{mg}$, and $20 \mathrm{mg}$ groups, respectively and significance was demonstrated for all three months. Sleep quality was significantly improved for all three months in the active treatment groups as well.

To date no published trials have directly compared the efficacy of indiplon to a FDA-approved agent for sleep. However, one trial examined next day effects using a fiveway crossover study in which adult patients received a single post-bedtime dose (four hours after lights-out) of indiplon IR $10 \mathrm{mg}$, indiplon IR $20 \mathrm{mg}$, zolpidem $10 \mathrm{mg}$, zopiclone $7.5 \mathrm{mg}$, and placebo. ${ }^{26}$ The primary outcome was to evaluate next day effects of the medications compared to placebo using the VAS-S, DSST, and the SCT. No significant differences in the VAS-S, DSST, or SCT were noted four or six hours post dose in the indiplon $10 \mathrm{mg}$ or $20 \mathrm{mg}$ groups. Baseline VAS-S values were $47.4 \pm 3$ in the zolpidem $10 \mathrm{mg}$ group, $41.6 \pm 3$ in the zopiclone $7.5 \mathrm{mg}$ group, and $48.1 \pm 3.2$ in the placebo group. Significant differences compared to placebo were noted in the VAS-S at four hours post-dose for zolpidem $(60.5 \pm 3 ; p=0.042)$ and zopiclone $(66.1 \pm 3 ; p<0.0001)$ with this persisting to six hours post-dose in the zopiclone group $(57.2 \pm 3.1 ; \mathrm{p}=0.002)$.

\section{Elderly studies}

Indiplon IR was specifically studied in elderly patients in four trials. ${ }^{18,26,32,33}$ Walsh and colleagues ${ }^{32}$ conducted a two-week study involving patients who met criteria for primary insomnia for at least three months comparing indiplon IR $5 \mathrm{mg}$ or $10 \mathrm{mg}$ to placebo. End points were self-recorded in patient diaries. The mean LSO significantly improved at week 1 with a value of $34.6 \pm 1.8$ minutes $(\mathrm{p}<0.0001)$ in the $5 \mathrm{mg}$ group and of $30.4 \pm 1.6$ minutes $(\mathrm{p}<0.0001)$ in the $10 \mathrm{mg}$ group, compared to placebo with a value of $47.7 \pm 2.5$ minutes. This significant difference in mean LSO was maintained at week 2 for both the $5 \mathrm{mg}(\mathrm{p}=0.0160)$ and $10 \mathrm{mg}(\mathrm{p}=0.0028)$ doses. Mean TST at week 1 was $312.2 \pm 5$ minutes in the placebo group, $340.3 \pm 5$ minutes $(\mathrm{p}<0.0001)$ in the $5 \mathrm{mg}$ group, and $360 \pm 5$ minutes ( $<<0.0001)$ in the $10 \mathrm{mg}$ group. TST remained significantly better at week 2 compared to placebo for the $5 \mathrm{mg}(\mathrm{p}=0.0064)$ and $10 \mathrm{mg}(\mathrm{p}=0.0015)$ doses. Significant improvement was also noted at week 1 for NAASO with values of $2 \pm 0.1,1.6 \pm 0.1(p=0.0002), 1.4 \pm 0.1$ $(\mathrm{p}<0.0001)$ in the placebo, $5 \mathrm{mg}$, and $10 \mathrm{mg}$ groups, respectively. At week 2, NAASO remained significant with values of $1.9 \pm 0.1,1.6 \pm 0.1(\mathrm{p}=0.0014), 1.5 \pm 0.1(\mathrm{p}<0.0001)$ in the placebo, $5 \mathrm{mg}$, and $10 \mathrm{mg}$ groups, respectively. The WASO was significant in the indiplon $10 \mathrm{mg}$ group at week 1 with $60.5 \pm 4.1$ minutes $(\mathrm{p}<0.0001)$ and week 2 with $69.8 \pm 4$ minutes $(\mathrm{p}=0.0112)$ compared to $83.3 \pm 4.1$ minutes at week 1 and $84.2 \pm 4$ minutes at week 2 in the placebo group. WASO was significant only in week 2 in the $5 \mathrm{mg}$ group with values at week 1 of $73.1 \pm 4$ minutes $(p=0.0725)$ and week 2 with $70.8 \pm 4$ minutes $(\mathrm{p}=0.0180)$. Sleep quality was also significantly improved in the $5 \mathrm{mg}$ group at week 1 $(\mathrm{p}<0.0001)$ and week $2(\mathrm{p}=0.0007)$ as well as the $10 \mathrm{mg}$ group at week $1(\mathrm{p}<0.0001)$ and week $2(\mathrm{p}=0.005)$, compared to placebo.

The longest indiplon IR trial in the elderly was a six-month open-label extension trial. Patients with a three-month or more history of primary insomnia self-evaluated the benefit of indiplon on their insomnia. ${ }^{18}$ Patients received either indiplon IR $5 \mathrm{mg}$ or $10 \mathrm{mg}$ as needed at bedtime. Only 81 of 121 patients completed six months of the study, with $72 \%$ of patients on the $5 \mathrm{mg}$ dose and $92 \%$ of patients on the $10 \mathrm{mg}$ dose reporting indiplon IR improved their insomnia. 
Table 4 Efficacy measures used in indiplon clinical trials ${ }^{38-40}$

\begin{tabular}{lll}
\hline Efficacy term & $\begin{array}{l}\text { Measured end } \\
\text { point }\end{array}$ & Definition \\
\hline $\begin{array}{l}\text { Latency to sleep onset (LSO)* } \\
\text { Latency to persistent sleep (LPS) }\end{array}$ & $\begin{array}{l}\text { Sleep onset } \\
\text { Sleep onset }\end{array}$ & $\begin{array}{l}\text { Time it takes to go from lying in bed to the beginning of sleep } \\
\text { An objective PSG measurement of the time it takes to fall } \\
\text { asleep and may also be defined as the first I0 minutes of } \\
\text { continuous sleep } \\
\text { Total sleep time (TST)* }\end{array}$ \\
Wake after sleep onset (WASO)* & Sleep duration & $\begin{array}{l}\text { Actual amount of sleep time which includes all stages of sleep } \\
\text { (Stages I-4 and REM sleep) }\end{array}$ \\
Number of Awakenings after sleep onset (NAASO)* & Sleep maintenance & $\begin{array}{l}\text { Amount of time spent awake after initial sleep onset until the } \\
\text { end of the sleep cycle }\end{array}$ \\
Sleep quality & Sleep maintenance & $\begin{array}{l}\text { Number of times a subject awakens from sleep during the } \\
\text { night }\end{array}$ \\
\hline
\end{tabular}

Note: *Objectively measured by PSG or subjectively measured by patient diary or post-sleep questionnaires. Abbreviations: PSG, polysomnogram; REM, rapid eye movement.

The efficacy of indiplon IR was also examined in a four-period crossover study in elderly patients with a diagnosis of primary insomnia comparing indiplon IR $5 \mathrm{mg}, 10 \mathrm{mg}$, or $20 \mathrm{mg}$ to placebo. ${ }^{33}$ PSG measured mean LPS was significantly improved with values of $13.8,10.4,9.8$, and 25.2 minutes in the indiplon IR $5 \mathrm{mg}, 10 \mathrm{mg}, 20 \mathrm{mg}$, and placebo groups, respectively $(p<0.001)$. Significant improvement in PSG measured mean TST was only demonstrated in the indiplon IR $10 \mathrm{mg}$ group with a value of 372.1 minutes $(\mathrm{p}=0.027)$ and in the $20 \mathrm{mg}$ group with a value of $385.6(\mathrm{p}<0.001)$ minutes. TST values for the $5 \mathrm{mg}$ and placebo groups were 363.7 and 354.4 minutes, respectively. Subjectively measured mean LSO was significantly improved with values of 28.8 minutes in the $5 \mathrm{mg}$ group, 24.7 minutes in the $10 \mathrm{mg}$ group, 20.2 minutes in the $20 \mathrm{mg}$ group, and 41.8 minutes in the placebo group $(\mathrm{p}<0.004)$. No difference in next day residual effects as measured by DSST, SCT, and VAS-S was found in the indiplon groups compared to placebo.

Farber and colleagues ${ }^{26}$ studied indiplon IR in an indirect manner with an approved comparative agent in elderly patients to evaluate next day residual effects. In a one-night, four-way crossover, single post-bedtime dose (four hours after lights-out) trial, indiplon IR $5 \mathrm{mg}$ and $10 \mathrm{mg}$ were compared to placebo and zopiclone $3.75 \mathrm{mg}$ as an active control. The primary outcome measured next day residual effects using the VAS-S, DSST, and the SCT. No significant difference in VAS-S or SCT was found in the medication arms versus placebo. Also, no significant difference was noted in the indiplon IR $5 \mathrm{mg}$ group versus the placebo group in the DSST at four, six, or eight hours post-dose. However, the indiplon IR $10 \mathrm{mg}$ group did demonstrate a significant difference at four hours post-dose compared to placebo $(p=0.022)$ in DSST, but no difference was noted at six and eight hours post-dose. Finally, zopiclone demonstrated a significant reduction in DSST at both four hours $(\mathrm{p}=0.002)$ and eight hours $(p=0.003)$ post-dose compared to placebo.

\section{Indiplon MR}

Indiplon has also been studied in a MR form. The MR dosage form provides drug initially and then gradually releases medication providing therapeutic drug concentrations for an extended period during the night. ${ }^{34}$ It should be noted that study data related to indiplon MR is limited and three of the studies are only available in abstract form..$^{35-37}$

\section{Adult studies}

A two-week study compared indiplon MR $30 \mathrm{mg}$ to placebo in adults with a diagnosis of primary insomnia for greater than three months..$^{35}$ LSO was 30 minutes in the indiplon MR group compared to 37 minutes in the placebo group ( $\mathrm{p}=0.0084)$ at week 1 and 27 minutes compared to 33 minutes at week $2(p=0.0131)$, respectively. Subjective TST was significantly improved at week 1 with 375 minutes in the indiplon MR group compared to 328 minutes in the placebo group $(\mathrm{p}<0.0001)$ and this continued at week 2 with 367 minutes in the indiplon MR group versus 336 minutes in the placebo group ( $p=0.0013)$. Subjective WASO was significantly improved at 54 minutes compared to 79 minutes at week one ( $\mathrm{p}<0.0001)$ and 51 minutes compared to 73 minutes at week $2(p=0.0003)$ in the indiplon MR and placebo groups, respectively. Sleep quality and NAASO were also significantly improved at weeks 1 and $2(\mathrm{p}<0.0001)$ compared to placebo (p-value not reported). 
Indiplon MR $40 \mathrm{mg}$ was studied in healthy male volunteers compared to placebo in a venipuncture model of insomnia. ${ }^{36}$ Blood samples were taken throughout the night to impair sleep initiation and sleep maintenance. Subjectively measured improvements in LSO were noted in the indiplon MR group at 30.2 minutes versus 72.2 minutes in the placebo group $(\mathrm{p}<0.001)$. Significant improvement in subjective TST was found in the indiplon MR group with 315.6 minutes versus 246.6 minutes in the placebo group $(p=0.02)$. The NAASO was improved, but not significantly in the indiplon MR group compared to placebo and this lack of significance was believed to be due to the multiple blood draws during the night. Overall patient rated sleep quality was significantly improved compared to placebo $(p=0.04)$. No change in next day residual effects was noted compared to baseline using the DSST, SCT, and VAS-S assessments.

\section{Elderly studies}

Indiplon MR $15 \mathrm{mg}$ was studied in elderly patients with primary insomnia of at least three months duration in a two-week trial. ${ }^{34}$ All data was self-recorded by patients in daily sleep diaries. Significant improvement in mean subjective TST occurred in the indiplon MR group at week 1 with a value of $376 \pm 4.2$ minutes $(p<0.0001)$ compared to the placebo group with a value of $327.5 \pm 4.4$ minutes. LSO was significantly improved in the indiplon group at weeks 1 and 2 with mean values of $22.0 \pm 1.1$ and $21.2 \pm$ 1.2 minutes $(\mathrm{p}<0.0001)$ compared to the placebo group at $34.9 \pm 1.8$ and $31 \pm 1.8$ minutes, respectively. Other significant findings at weeks 1 and 2 in the indiplon MR group included mean WASO with $55.7 \pm 3.1$ minutes at week 1 $(\mathrm{p}<0.001)$ and $56.4 \pm 3.6$ minutes at week $2(\mathrm{p}<0.0001)$, compared to the placebo group at $84.9 \pm 3.2$ minutes at week 1 and $80.5 \pm 3.7$ minutes at week 2 . Mean NAASO significantly improved in the indiplon MR group to $1.4 \pm 0.1$ at week $1(\mathrm{p}<0.0001)$ and $1.3 \pm 0.1$ at week $2(\mathrm{p}<0.0001)$ compared to $2 \pm 0.1$ at week 1 and $1.9 \pm 0.1$ at week 2 in the placebo group. Sleep quality was also significantly improved in week 1 at $64 \%(\mathrm{p}<0.0001)$ compared to $32 \%$ and in week 2 at $57 \%(\mathrm{p}<0.002)$ compared to $35 \%$ in the indiplon MR and placebo groups, respectively. The authors did note that the study design may not completely represent elderly patients with chronic insomnia since patients with unstable medical or psychiatric illnesses were excluded and due to the strict time-in-bed requirements of the study.

Indiplon MR was examined in elderly patients comparing doses of $10 \mathrm{mg}, 20 \mathrm{mg}, 30 \mathrm{mg}$, and $35 \mathrm{mg}$ to placebo with each patient receiving each dose of medication on two consecutive nights. ${ }^{37}$ Significant improvement in mean LPS values was found with values of 26 minutes in the placebo group, 17.6 minutes in the $10 \mathrm{mg}$ group, 11.2 minutes in the $20 \mathrm{mg}$ group, 11 minutes in the $30 \mathrm{mg}$ group, and 9.9 minutes in the $35 \mathrm{mg}$ group $(\mathrm{p}<0.01)$. Mean sleep efficiency was significantly improved in the $20 \mathrm{mg}, 30 \mathrm{mg}$, and $35 \mathrm{mg}$ dosages only $(\mathrm{p}<0.0001)$. WASO in the placebo group was 103.2 minutes and 102.1 minutes in the $10 \mathrm{mg}$ group (NS). Significant improvements in WASO occurred only in the $20 \mathrm{mg}$ ( 87.3 minutes), $30 \mathrm{mg}$ ( 81.9 minutes), and $35 \mathrm{mg}$ (83 minutes) dosage groups, compared to placebo $(103.2$ minutes $)(\mathrm{p}<0.01)$.

\section{Safety and tolerability Adult and elderly adverse events Indiplon IR}

The clinical studies reporting specific adverse events related to indiplon are summarized in Table 5. ${ }^{26,27,29,31,32,41}$ Other studies did not report details on adverse events but reported no serious adverse events. ${ }^{18,28,30,33}$ Based on available study data, no specific serious adverse events attributable to indiplon have been identified. Currently it is difficult to determine if there is a dose dependent increase in the incidence of specific adverse events. A 12-month randomized, double-blind, safety and tolerability study using as needed indiplon IR $10 \mathrm{mg}$ or $20 \mathrm{mg}$ in 536 adults with insomnia found indiplon to be well tolerated without any dose dependent side effects. ${ }^{41}$ However, a three-month study by Scharf and colleagues ${ }^{31}$ reported discontinuation rates secondary to adverse events as higher in the indiplon $20 \mathrm{mg}$ group (19.7\%) compared to the indiplon $10 \mathrm{mg}$ group (6.4\%) and placebo (5.2\%). Adverse events in this study were reported as transient, with median durations of 3-19 days for the adverse events occurring at a $>5 \%$ incidence (see Table 5).

Indiplon's safety in the elderly was specifically evaluated in four studies, ${ }^{18,26,32,33}$ two of which are only available in abstract form. ${ }^{18,33}$ The largest of these studies evaluated two weeks of nightly use of indiplon IR $5 \mathrm{mg}$ and $10 \mathrm{mg}$ vs placebo in patients aged $65-80$ years. A dose-related increase in study discontinuation due to adverse events was reported ( $8.4 \%$ on $10 \mathrm{mg}, 5 \%$ on $5 \mathrm{mg}$, and $0.8 \%$ on placebo). ${ }^{32}$

\section{Rebound insomnia}

The potential for rebound insomnia following indiplon discontinuation was examined in two adult studies ${ }^{28,31}$ and one elderly study. ${ }^{32}$ The first adult study found after three months of consecutive nightly use, rebound insomnia occurred 
Table 5 Clinical studies with reported ADR's with indiplon IR greater than placebo

\begin{tabular}{|c|c|c|c|c|c|c|}
\hline \multirow[t]{2}{*}{ Author (year) } & \multirow[t]{2}{*}{ ADRs Incidence (\%) } & \multirow[t]{2}{*}{ Specific ADR } & \multicolumn{4}{|c|}{ Incidence (\%) } \\
\hline & & & Placebo & Indiplon 5 mg & Indiplon 10 mg & Indiplon $20 \mathrm{mg}$ \\
\hline Farber $(2008)^{26}$ & Placebo 2.8 & Headache & 0 & 2.8 & 2.8 & $\mathrm{~N} / \mathrm{A}$ \\
\hline \multirow[t]{2}{*}{ Elderly $\mathrm{N}=36$} & Indiplon 5 mg 2.8 & & & & & \\
\hline & Indiplon 10 mg 2.8 & & & & & \\
\hline Farber $(2008)^{26}$ & Placebo 8.6 & Tiredness & 0 & $N / A$ & 0 & 2.9 \\
\hline \multirow[t]{2}{*}{ Adults $\mathrm{N}=35$} & Indiplon 10 mg 5.9 & Headache & 5.7 & & 5.9 & 5.9 \\
\hline & Indiplon 20 mg 11.8 & Retarded motor activity & 0 & & 0 & 2.9 \\
\hline Roth $(2007)^{27}$ & Placebo $=26$ & Headache & 2.3 & $\mathrm{~N} / \mathrm{A}$ & 2.4 & 6.7 \\
\hline \multirow[t]{2}{*}{ Adults $N=264$} & Indiplon 10 mg = 39 & Somnolence & 3.5 & & 6.0 & 7.8 \\
\hline & Indiplon 20 mg = 34 & & & & & \\
\hline Rosenberg $(2007)^{29}$ & Placebo $=10$ & Headache & 1 & $\mathrm{~N} / \mathrm{A}$ & 2 & 3.1 \\
\hline \multirow[t]{2}{*}{ Adults $N=593$} & Indiplon $10 \mathrm{mg}=10.1$ & Nausea & 0.5 & & 0.5 & 2.1 \\
\hline & Indiplon $20 \mathrm{mg}=15.5$ & & & & & \\
\hline Scharf $(2007)^{31}$ & Not reported & URI & 5.2 & $\mathrm{~N} / \mathrm{A}$ & 5.9 & 6 \\
\hline \multirow[t]{4}{*}{ Adults $\mathrm{N}=702$} & & Amnesia & 0 & & 1.3 & 6.4 \\
\hline & & Dizziness & 3 & & 4.7 & 6.9 \\
\hline & & Headache & 6.9 & & 8.5 & 9 \\
\hline & & Somnolence & 1.3 & & 3 & 7.3 \\
\hline Walsh $(2007)^{32}$ & Placebo $=42$ & Headache & 2.5 & 7.5 & 5.9 & $\mathrm{~N} / \mathrm{A}$ \\
\hline \multirow[t]{5}{*}{ Elderly N = 358} & Indiplon $5 \mathrm{mg}=3 \mathrm{I} . \mathrm{I}$ & Somnolence & 0 & 1.7 & 5 & \\
\hline & Indiplon $10 \mathrm{mg}=38.3$ & Depression & 0 & 5 & 0 & \\
\hline & & Decreased appetite & 0 & 5.9 & 0 & \\
\hline & & Dizziness & 1.7 & 4.2 & 6.7 & \\
\hline & & Nausea & 0 & 5 & 1.7 & \\
\hline Black $^{\mathrm{a}}(2006)^{4 l}$ & Not reported & Headache & & & 11.8 & 8.7 \\
\hline \multirow[t]{4}{*}{ Adults $N=536$} & & Back pain & & & 7.9 & $N / A$ \\
\hline & & Somnolence & & & 7.9 & $\mathrm{~N} / \mathrm{A}$ \\
\hline & & URI & & & $\mathrm{N} / \mathrm{A}$ & 6.5 \\
\hline & & Nasopharyngitis & & & $\mathrm{N} / \mathrm{A}$ & 5.9 \\
\hline
\end{tabular}

Note: ${ }^{\text {aAbstract-only data. }}$

Abbreviations: ADR, adverse drug reaction; URI, upper respiratory infection; N/A, not applicable.

on the first night in $22.1 \%$ of subjects on indiplon $20 \mathrm{mg}$, $18.9 \%$ on indiplon $10 \mathrm{mg}$, and $8.8 \%$ on placebo; however, occurrence was much less on the second night, with rates of $11.4 \%, 11.1 \%$, and $1.1 \%$ of patients, respectively (no $p$ value reported). ${ }^{31}$ In the second adult study, rebound insomnia, assessed subjectively and by PSG, was not found with indiplon after five weeks of use. ${ }^{28}$ In a two-week elderly study, rebound insomnia was noted the first night after stopping active treatment in $2 \%$ of the placebo group, $12.9 \%$ of the $5 \mathrm{mg}$ group $(\mathrm{p}=0.004)$, and $8.6 \%(\mathrm{p}<0.05)$ of the $10 \mathrm{mg}$ group. ${ }^{32}$ These values decreased to $0 \%, 1.1 \%$, and $1.1 \%$ in the placebo, $5 \mathrm{mg}$, and $10 \mathrm{mg}$ groups, respectively on night 2 after discontinuing therapy (NS).

\section{Withdrawal effects}

The potential for indiplon to cause withdrawal effects was assessed in two adult studies ${ }^{28,31}$ and one elderly study ${ }^{32}$ using the Benzodiazepine Withdrawal Symptoms Questionnaire (BWSQ). The BWSQ uses a three-point severity scale with 20 questions designed to evaluate withdrawal symptoms from medications that work at $\mathrm{GABA}_{\mathrm{A}}$ receptors. ${ }^{42}$ After three months of indiplon use, no discontinuation effects were seen in adults at the end of treatment and one week after stopping therapy. ${ }^{31}$ There was also no difference in discontinuation effects compared among the $10 \mathrm{mg}$ and $20 \mathrm{mg}$ groups in a five-week adult trial. ${ }^{28}$ Indiplon discontinuation following a two-week elderly study did not cause any withdrawal symptoms either. ${ }^{32}$

\section{Abuse potential}

The abuse potential of indiplon was studied using large doses of indiplon ( $30 \mathrm{mg}, 50 \mathrm{mg}$, and $80 \mathrm{mg}$ ) versus placebo and triazolam $(0.25 \mathrm{mg}, 0.5 \mathrm{mg}$, and $0.75 \mathrm{mg})$ in 21 adult patients with a history of recreational substance abuse ${ }^{43}$ Investigators 
concluded that the abuse potential of indiplon at these high doses was not different when compared to triazolam; however, psychomotor and cognitive impairment might be less with indiplon versus triazolam.

\section{Daytime residual effects}

Studies evaluating daily and as needed use for up to 12 months in adults, and up to six months in the elderly, have found indiplon IR to be relatively safe, ${ }^{18,41}$ without complaints of next day residual effects. ${ }^{27,28,31,33}$ Details of these effects were previously described in the clinical trials section of this article.

\section{Indiplon MR safety}

The longest and largest study to date for the MR formulation investigated the use of indiplon MR $15 \mathrm{mg}$ for two weeks in elderly patients. ${ }^{34}$ Forty-four percent of patients in the indiplon MR group had an adverse reaction compared to $28 \%$ in the placebo group, with $<1 \%$ deemed severe. The following adverse events occurred at an incidence two-fold greater than placebo: dizziness $(8 \%)$, headache $(6 \%)$, and somnolence (4\%). No falls were reported. There was evidence of rebound insomnia on the first night after discontinuation, but incidence returned to baseline by the second night. No evidence of withdrawal symptoms was found using the BWSQ. Safety data from the three other trials looking at the MR formulation are only available in abstract form but report no serious adverse reactions. ${ }^{35-37}$

\section{Dosing and administration}

If granted FDA approval, it is anticipated that indiplon IR will be available in $5 \mathrm{mg}$ and $10 \mathrm{mg}$ strengths. It should be noted that efficacy studies in adults have used indiplon IR doses of $10 \mathrm{mg}$ and $20 \mathrm{mg}^{27,28,31}$ while efficacy studies in the elderly have used indiplon IR doses of $5 \mathrm{mg}, 10 \mathrm{mg}$, and $20 \mathrm{mg} .{ }^{18,32,33}$ Studies have assessed daily nighttime dosing, as needed dosing, and as needed post-bedtime dosing.

\section{Contraindications, warnings, and precautions}

Although labeling is not currently available, indiplon may not be an option for all patients. As with any medication, indiplon should be contraindicated in anyone with previous hypersensitivity to this medication. In 2007 the FDA recommended a label change for sleep-inducing agents. This label change provided warnings regarding anaphylaxis, angioedema, and other "complex sleep-related behaviors which may include sleep-driving, making phone calls and preparing and eating food (while asleep)". ${ }^{44}$ If approved, indiplon will likely receive the same warning. Because of its hepatic metabolism, use should be avoided in those with impaired liver function. Alcohol use $>5$ drinks/day or $>14$ drinks/week was excluded in most trials; however, one study showed there was little or no interaction when indiplon IR $10 \mathrm{mg}$ was co-administered with ethanol in 10 healthy patients. ${ }^{25}$ Because indiplon acts centrally, concomitant alcohol use with indiplon should probably be avoided. Furthermore, most trials excluded concomitant use of centrally acting medications (anxiolytics, anticonvulsants, narcotics, antihistamines). More studies are needed to determine if there would be any difference in the effectiveness or safety of indiplon when used with other centrally acting medications.

Benzodiazepine-like withdrawal symptoms were not reported after discontinuation of indiplon during clinical trials, ${ }^{28,31,32}$ however use should probably be avoided in those with previous dependence on other centrally acting medications, such as benzodiazepines or other hypnotics. One study in a small number of patients with a history of substance abuse found that the potential for abuse of large doses of indiplon was not different when compared with triazolam. ${ }^{43}$

\section{Special populations}

Indiplon IR and MR have been studied in patients aged 18-80 years with lower doses in the elderly population. Neither the IR nor MR formulations have been studied in those $<18$ years of age or in pregnant women, therefore avoiding use of indiplon in these populations is warranted until more safety and efficacy data is available. Two of the three requirements identified in the 2007 FDA Approvable Letter included an objective/subjective clinical trial in the elderly and a pre-clinical study for use during the third trimester of pregnancy. ${ }^{10}$

\section{Discussion}

Indiplon may have several advantages to offer if approved for the treatment of primary insomnia. Indiplon IR appears safe and efficacious in the treatment of insomnia in both adult and elderly populations as demonstrated by improvements in LPS, LSO, TST, WASO, NAASO, and sleep quality. A potentially unique item to indiplon is post-bedtime dosing or middle of the night dosing. ${ }^{27}$ However, zaleplon has been used off label in a post-bedtime or middle of the night dosing method similar to indiplon. ${ }^{45}$ Indiplon appears to be well tolerated with no specific serious adverse events identified during clinical trials. However, the FDA has 
requested a study comparing adverse events of indiplon versus an FDA approved product for the treatment of primary insomnia. ${ }^{10}$

A potential issue related to indiplon in the treatment of primary insomnia is that the majority of adult studies used the $10 \mathrm{mg}$ and $20 \mathrm{mg}$ dosages and the elderly studies used $5 \mathrm{mg}$ and $10 \mathrm{mg}$ dosages. FDA approval was sought only for the $5 \mathrm{mg}$ and $10 \mathrm{mg}$ dosages. It is unclear if this will affect the potential efficacy in the adult population by seeking approval for only one of the dosages studied in adults. Based on available data, it does not appear the $5 \mathrm{mg}$ dose was studied in adults. Also, it should be noted that at various time points in clinical studies, indiplon was unable to demonstrate statistical improvement in values such as TST, WASO, NAASO, and sleep quality depending on the dose of medication and the duration of the trial. Even though indiplon was studied specifically in the elderly, the FDA did request an additional safety and efficacy trial. Indiplon studies also excluded patients with current psychiatric illnesses and patients with acute medical illnesses which are two very common areas of use for sedative hypnotics. At the time of this writing, it is not known what specific indications indiplon will have or if it will have a specific advantage or indication over other products already approved for the treatment of primary insomnia. The post-bedtime or middle of the night dosing advantage of indiplon may be offset by the off label use of zaleplon in such a dosing method. Also, it is not known if indiplon will be indicated for sleep maintenance based on its short half-life. The MR formulation was investigated for that indication, however, indiplon MR received a Not Approvable Letter in 2006 and it does not appear that its approval was pursued following that letter. From the current Approvable Letter it appears that sleep initiation or as needed post-bedtime dosing would be the primary indications for indiplon. Finally, the cost of indiplon is unknown and it is difficult to predict how insurance companies would view indiplon compared to other nonbenzodiazepine sedative hypnotics, some of which are available generically.

\section{Conclusion}

Indiplon IR appears safe and effective in the treatment of insomnia in both adult and elderly populations. Indiplon appears to be well tolerated with few side effects and no specific serious adverse events reported in clinical trials. Studies evaluating daily and as needed indiplon IR dosing did not reveal complaints of next day residual or withdrawal effects. The abuse potential of indiplon appears minimal, and it has a low, transient incidence of rebound insomnia.
If FDA approved, indiplon may provide a unique dosing option for the treatment of insomnia related to post-bedtime or middle of the night dosing.

\section{Acknowledgments}

We would like to acknowledge the administrative assistance of Barbara Papik, Medical Librarian Avera Sacred Heart Hospital Medical Library, Yankton, South Dakota in literature searching for this manuscript.

\section{Disclosure}

The authors report no conflicts of interest in this work.

\section{References}

1. American Psychiatric Association. Diagnostic and statistical manual of mental disorders - text revision: DSM-IV-TR, 4th ed. Washington, DC: American Psychiatric Publishing, Inc.; 2000.

2. National Sleep Foundation. 2005 Sleep in America Poll, Washington DC. Cited Feb 13, 2009. Available from: http://www.kintera.org/atf/cf/ \{F6BF2668-A1B4-4FE8-8D1A-A5D39340D9CB\}/2005_summary_ of_findings.pdf.

3. Walsh JK. Clinical and socioeconomic correlates of insomnia. J Clin Psychiatry. 2004;65(Suppl 8):13-19.

4. NIH state-of-the-science conference statement on manifestations and management of chronic insomnia in adults. 2005. NIH Consens Sci Statements. 22; 2:1-36. Cited Feb 13, 2009. Available from: http://www. ahrq.gov/clinic/epcsums/insomnsum.htm.

5. Silber MH. Chronic insomnia. N Engl J Med. 2005;353(8):803-810.

6. Morin AK, Jarvis CI, Lynch AM. Therapeutic options for sleepmaintenance and sleep-onset insomnia. Pharmacotherapy. 2007;27(1): 89-110.

7. Benca RM. Diagnosis and treatment of chronic insomnia: a review. Psychiatr Serv. 2005;56(3):332-343.

8. Foster AC, Pelleymounter MA, Cullen MJ, et al. In vivo pharmacological characterization of indiplon, a novel pyrazolopyrimidine sedativehypnotic. J Pharmacol Exp Ther. 2004;311(2):547-559.

9. Sullivan SK, Petroski RE, Verge G, Gross RS, Foster AC, Grigoriadis DE. Characterization of the interaction of indiplon, a novel pyrazolopyrimidine sedative-hypnotic, with the GABA A receptor. J Pharmacol Exp Ther. 2004;311(2):537-546.

10. Additional pipeline programs: Indiplon. Neurocrine Biosciences, Inc Web site. Cited Feb 13, 2009. Available from: http://www.neurocrine. com/index.cfm?navId $=25$.

11. Neurocrine Biosciences reports fourth quarter and year-end 2008 results. Neurocrine Biosciences, Inc Web site. Cited Feb 13, 2009 . Available from: http://phx.corporate-ir.net/phoenix.zhtml?c $=68817 \& p=$ irolnewsArticle\&highlight $=\& \mathrm{ID}=1251507$.

12. Barnard EA, Skolnick $P$, Olsen RW, et al. International union of pharmacology. xv. subtypes of $\gamma$-aminobutyric acid ${ }_{A}$ receptors: classification on the basis of subunit structure and receptor function. Pharmacol Rev. 1998;50(2):291-313.

13. Möhler H, Fritschy JM, Rudolph U. A new benzodiazepine pharmacology. J Pharmacol Exp Ther. 2002;300(1):2-8.

14. Rudolph U, Crestani F, Benke D, et al. Benzodiazepine actions mediated by specific $\gamma$-aminobutyric acid ${ }_{\mathrm{A}}$ receptor subtypes. Nature. 1999;401(6755):796-800.

15. Petroski RE, Pomeroy JE, Das R, et al. Indiplon, is a high-affinity positive allosteric modulator with selectivity for $\alpha 1$ subunit-containing GABA A $_{\mathrm{A}}$ receptors. J Pharmacol Exp Ther. 2006;317(1):369-377.

16. Soldatos CR, Dikeos DG, Whitehead A. Tolerance and rebound insomnia with rapidly eliminated hypnotics: a meta-analysis of sleep laboratory studies. Int Clin Psychopharmacol. 1999;14(5):287-303. 
17. Jochelson P, Chen TK, Farber R, Campbell B. Lack of pharmacological and pharmacokinetic tolerance following repeat dosing of indiplon (NBI-34060) [abstract]. Sleep. 2003;26(Suppl):A85-A86.

18. Moscovitch A, Burke J, Farber R. Long-term use of indiplon in elderly patients with chronic insomnia [abstract]. Sleep. 2006;29(Suppl):A254.

19. Madan A, Fisher A, Jin L, Chapman D, Bozigian HP. In vitro metabolism of indiplon and an assessment of its drug interaction potential. Xenobiotica. 2007;37(7):736-752.

20. Rogowski R, Garber M, Bozigian H, Jochelson P, Farber R, Campbell B. NBI-34060 (a non-benzodiazepine sedative-hypnotic): lack of a pharmacokinetic gender effect [abstract]. Sleep. 2002;25(Suppl):A415.

21. Jochelson P, Rogowski R, Burke J, et al. The pharmacokinetics of the non-benzodiazepine sedative-hypnotic, NBI-34060 in elderly subjects [abstract]. Sleep. 2002;25(Suppl):A415-A416.

22. Bozigian H, Chen TK, Gately N, Boyd M. Indiplon dose-proportional pharmacokinetics [abstract]. J Clin Pharmacol. 2005;45:1078.

23. Abdulnabi R, Janiczek N, Corrigan B, Hershberger E, Farber R. Indiplon and SSRIs: Lack of pharmacodynamic and pharmacokinetic interactions [abstract]. J Clin Pharmacol. 2005;45:1077.

24. Abel B, Corrigan B, Hershberger E, et al. Indiplon and warfarin, theophylline and digoxin: lack of pharmacokinetic interactions [abstract]. J Clin Pharmacol. 2005;45:1077.

25. Berkowitz DV, Scharf MB, Jochelson P. The co-administration of indiplon (NBI-34060) and alcohol lacks pharmacokinetic and pharmacodynamic interactions [abstract]. Sleep. 2003;26 Suppl:A81.

26. Farber RH, Burke PJ. Post-bedtime dosing with indiplon in adults and the elderly: results from two placebo-controlled, active comparator crossover studies in healthy volunteers. Curr Med Res Opin. 2008;24(3):837-846.

27. Roth T, Zammit GK, Scharf MB, Farber R. Efficacy and safety of as-needed, post bedtime dosing with indiplon in insomnia patients with chronic difficulty maintaining sleep. Sleep. 2007;30(12):1731-1738.

28. Walsh JK, Rosenberg R, Roth T, Lankford DA, Jochelson P. Treatment of primary insomnia for five weeks with indiplon-IR [abstract]. Sleep. 2004;27(Suppl):A259.

29. Rosenberg R, Roth T, Scharf MB, Lankford DA, Farber R. Efficacy and tolerability of indiplon in transient insomnia. J Clin Sleep Med. 2007;3(4):374-379.

30. Roth T, Walsh JK, Rogowski R, Farber R, Burke J, Jochelson P. Efficacy and tolerability of indiplon (NBI-34060) solution in healthy adults in a model of transient insomnia [abstract]. Sleep. 2003;26(Suppl):A87.

31. Scharf MB, Black J, Hull S, Landin R, Farber R. Long-term nightly treatment with indiplon in adults with primary insomnia: results of a double-blind, placebo-controlled, 3-month study. Sleep. 2007;30(6): 743-752.
32. Walsh JK, Moscovitch A, Burke J, Farber R, Roth T. Efficacy and tolerability of indiplon in older adults with primary insomnia. Sleep Med. 2007;8(7-8):753-759.

33. Scharf MB, Rosenburg R, Cohn M, et al. Safety and efficacy of immediate release indiplon (NBI-34060) in elderly patients with insomnia [abstract]. Sleep. 2003;26(Suppl):A85.

34. Lydiard RB, Lankford DA, Seiden DJ, Landin R, Farber R, Walsh JK. Efficacy and tolerability of modified-release indiplon in elderly patients with chronic insomnia: results of a 2-week double-blind, placebocontrolled trial. J Clin Sleep Med. 2006;2(3):309-315.

35. Jochelson P, Scharf M, Roth T, Walsh JK, Garber M. Efficacy of indiplon in inducing and maintaining sleep in patients with chronic sleep maintenance insomnia [abstract]. Sleep. 2004;27(Suppl):A262.

36. Jochelson P, Bozigian H, Garber M, et al. The activity of modified release indiplon (NBI-34060) in a transient nighttime venipuncture model [abstract]. Sleep. 2003;26(Suppl):A84.

37. Walsh JK, Lankford DD, Krystal A, et al. Efficacy and tolerability of four doses of indiplon (NBI-34060) modified-release in elderly patients with sleep maintenance insomnia [abstract]. Sleep. 2003;26(Suppl):A78.

38. Jhaveri M, Seal B, Pollack M, Wertz D. Will insomnia treatments produce overall cost savings to commercial managed-care plans? A predictive analysis in the United States. Curr Med Res Opin. 2007;23(6): 1431-1443.

39. Krystal AD. The effect of insomnia definitions, terminology, and classifications on clinical practice. J Am Geriatr Soc. 2005;53(7 Suppl): S258-S263.

40. Chokroverty S, Daroff RB, editors. Sleep disorders medicine: basic science, technical considerations, and clinical aspects. 2nd ed. Boston: Butterworth-Heinemann; 1999.

41. Black J, Burke J, Bell J, Farber R. Safety and tolerability of long-term treatment with indiplon: results of a randomized 12-month study [abstract]. Sleep. 2006;29(Supp1):A255.

42. Tyrer P, Murphy S, Riley P. The benzodiazepine withdrawal symptom questionnaire. J Affect Disord. 1990;19(1):53-61.

43. Carter LP, Griffiths RR, Suess PE, Casada JH, Wallace CL, Roache JD. Relative abuse liability of indiplon and triazolam in humans: a comparison of psychomotor, subjective, and cognitive effects. J Pharmacol Exp Ther. 2007;322(2):749-759.

44. FDA News: FDA Requests Label Change for All Sleep Disorder Drug Products. US Food and Drug Administration Web site. Cited Mar 13, 2009. Available from: http://www.fda.gov/bbs/topics/NEWS/2007/ NEW01587.html.

45. Weitzel KW, Wickman JM, Augustin SG, Strom JG. Zaleplon: a pyrazolopyrimidine sedative-hypnotic agent for the treatment of insomnia. Clin Ther. 2000;22(11):1254-1267.
Drug Design, Development and Therapy

\section{Publish your work in this journal}

Drug Design, Development and Therapy is an international, peerreviewed open-access journal that spans the spectrum of drug design and development through to clinical applications. Clinical outcomes, patient safety, and programs for the development and effective, safe, and sustained use of medicines are a feature of the journal,

\section{Dovepress}

which has also been accepted for indexing on PubMed Central. The manuscript management system is completely online and includes a very quick and fair peer-review system, which is all easy to use. Visit http://www.dovepress.com/testimonials.php to read real quotes from published authors 